\title{
Ig-like domain 6 of VCAM-1 is a potential therapeutic target in TNFo-induced angiogenesis
}

\author{
Taek-Keun Kim ${ }^{1,3}$, Chang Sik Park ${ }^{1,3}$, Hee-Jun Na ${ }^{1}$, Kangseung Lee ${ }^{1}$, Aerin Yoon ${ }^{2}$, Junho Chung ${ }^{2}$ and \\ Sukmook Lee ${ }^{1}$
}

Tumor necrosis factor alpha (TNF $\alpha$ )-induced angiogenesis plays important roles in the progression of various diseases, including cancer, wet age-related macular degeneration, and rheumatoid arthritis. However, the relevance and role of vascular cell adhesion molecule-1 (VCAM-1) in angiogenesis have not yet been clearly elucidated. In this study, VCAM-1 knockdown shows VCAM-1 involvement in TNF $\alpha$-induced angiogenesis. Through competitive blocking experiments with VCAM-1 Ig-like domain 6 (VCAM-1-D6) protein, we identified VCAM-1-D6 as a key domain regulating TNF $\alpha$-induced vascular tube formation. We demonstrated that a monoclonal antibody specific to VCAM-1-D6 suppressed TNF $\alpha$-induced endothelial cell migration and tube formation and TNF $\alpha$-induced vessel sprouting in rat aortas. We also found that the antibody insignificantly affected endothelial cell viability, morphology and activation. Finally, the antibody specifically blocked VCAM-1-mediated cell-cell contacts by directly inhibiting VCAM-1-D6-mediated interaction between VCAM-1 molecules. These findings suggest that VCAM-1-D6 may be a potential novel therapeutic target in TNF $\alpha$-induced angiogenesis and that antibody-based modulation of VCAM-1-D6 may be an effective strategy to suppress TNF $\alpha$-induced angiogenesis.

Experimental \& Molecular Medicine (2017) 49, e294; doi:10.1038/emm.2016.147; published online 17 February 2017

\section{INTRODUCTION}

Angiogenesis is the process by which new blood vessels form from pre-existing vessels. It is closely associated with the progression of a variety of diseases, including cancer, wet age-related macular degeneration (AMD), glaucoma, diabetic retinopathy and rheumatoid arthritis. ${ }^{1-4}$ In pathological conditions, angiogenesis is tightly controlled by the coordinated actions of numerous upregulated angiogenic factors. ${ }^{5}$ Although vascular endothelial growth factor (VEGF)-dependent angiogenesis plays a role in the progression of certain diseases, ${ }^{6,7}$ increased attention is being paid to tumor necrosis factor alpha $(\mathrm{TNF} \alpha)$-induced angiogenesis implicated in the progression of cancer, wet AMD and rheumatoid arthritis. ${ }^{8-13}$ Bevacizumab, a humanized antibody to VEGF, ranibizumab, a fragment antigen-binding (Fab) fragment of bevacizumab and aflibercept (VEGF-Trap) are the leading biological drugs targeting VEGF, and are used in clinics to suppress VEGF-dependent abnormal angiogenesis in the progression of cancers and wet AMD. ${ }^{14-17}$
However, resistance to these drugs remains a major hurdle in improving clinical outcomes. ${ }^{18,19}$ To this end, we focused on identifying a novel therapeutic target and elucidating its functional roles and mechanisms of action in angiogenesis.

Vascular cell adhesion molecule-1 (VCAM-1) is a $90-\mathrm{kDa}$ glycoprotein that is inducible and predominantly expressed in endothelial cells upon activation by any one of many extracellular stimuli, including reactive oxygen species and proinflammatory cytokines, such as TNF $\alpha$ and interleukin-1. ${ }^{20,21}$ VCAM-1 is a type I transmembrane protein that consists of an extracellular domain containing seven homologous immunoglobulin (Ig)-like domains, a transmembrane domain and a cytosolic domain. ${ }^{22}$ During an inflammatory response, VCAM-1 acts as a cell adhesion molecule by directly interacting with $\alpha 4 \beta 1$ integrin expressed on leukocytes via VCAM-1's Ig-like domains 1 and 4 within the extracellular domain. ${ }^{23}$ This molecular interaction plays a key role in the recruitment and association of leukocytes with activated endothelial cells.

\footnotetext{
${ }^{1}$ Laboratory of Molecular Cancer Therapeutics, Research Center, Scripps Korea Antibody Institute, Chuncheon, Republic of Korea and ${ }^{2}$ Department of Biochemistry and Molecular Biology, College of Medicine, Seoul National University, Seoul, Republic of Korea

${ }^{3}$ These authors contributed equally to this work.

Correspondence: Professor J Chung, Department of Biochemistry and Molecular Biology, College of Medicine, Seoul National University, Seoul 110-799, Republic of Korea.

E-mail: jjhchung@snu.ac.kr

or Dr S Lee, Laboratory of Molecular Cancer Therapeutics, Research Center, Scripps Korea Antibody Institute, 1 Kangwondaehak-gil, Chuncheon, Gangwondo 200-701, Republic of Korea.

E-mail: Lees@skai.or.kr

Received 2 May 2016; revised 7 October 2016; accepted 14 October 2016
} 
However, despite an increasing focus on VCAM-1 in inflammatory disorders, including immune rejection and atherosclerosis, ${ }^{24-28}$ the functional role and molecular mechanism of VCAM-1 in TNF $\alpha$-induced angiogenesis have not yet been clearly identified.

In this study, using VCAM-1 knockdown and competitive blocking experiments with VCAM-1 Ig-like domain 6 (VCAM-1-D6) protein, we obtained evidence of the role VCAM-1 plays in TNF $\alpha$-induced angiogenesis and identified VCAM-1D6 as a key domain in the regulation of the angiogenesis. With a monoclonal antibody specific to VCAM-1-D6 that we developed, we demonstrated that the antibody significantly and specifically suppressed TNF $\alpha$-induced angiogenesis without affecting endothelial cytotoxicity. We propose a mechanism of action in TNF $\alpha$-induced angiogenesis whereby VCAM-1-D6 plays a key role in endothelial cell-cell contact and the antibody acts as an interaction blockade directly inhibiting the VCAM-1D6-mediated interaction between VCAM-1 molecules on adjacent endothelial cells. In summary, our findings suggest that VCAM-1-D6 is a potential novel therapeutic target in TNF $\alpha$-induced angiogenesis and that antibody-based modulation of VCAM-1-D6 is an effective strategy to suppress TNF $\alpha$ induced angiogenesis.

\section{MATERIALS AND METHODS}

\section{Cell culture and transfection}

Human umbilical vein endothelial cells (HUVECs; Lonza, Basel, Switzerland) were maintained in endothelial growth medium (EGM; Lonza) at $37^{\circ} \mathrm{C}$ in a humidified incubator with $5 \% \mathrm{CO}_{2}$ (Panasonic Healthcare Company, Tokyo, Japan). Human embryonic kidney 293F (HEK293F) cells were maintained in Freestyle expression medium (Invitrogen/Life Technologies, Carlsbad, CA, USA) supplemented with $1 \%(\mathrm{v} / \mathrm{v})$ penicillin/streptomycin in a humidified Multitron incubation shaker (Infors HT, Basel, Switzerland) at $37^{\circ} \mathrm{C}$ in $8 \% \mathrm{CO}_{2}$. HUVECs were grown to $50-80 \%$ confluence and transiently transfected with ON-TARGETplus SMARTpool siRNA targeting VCAM-1 (Thermo Fisher Scientific, Waltham, MA, USA) using Lipofectamine 2000 transfection reagent (Invitrogen), according to the manufacturer's instructions.

\section{Flow cytometry}

Expression of VCAM-1 on the surface of HUVECs was evaluated by incubating $2 \times 10^{5}$ HUVECs in EGM in the absence or presence of $20 \mathrm{ng} \mathrm{ml}^{-1}$ human TNF $\alpha$ (hTNF $\alpha$; Millipore, Billerica, MA, USA) for $24 \mathrm{~h}$. After harvesting and washing with phosphate-buffered saline solution (PBS), the cells were fixed in $4 \%$ paraformaldehyde (PFA) for 20 min at room temperature. After blocking with PBS containing 1\% bovine serum albumin (BSA) for $1 \mathrm{~h}$ at room temperature, the cells were incubated first with mouse anti-VCAM-1 monoclonal antibody $\left(1 \mu \mathrm{g} \mathrm{ml}^{-1}\right.$; Abcam, Cambridge, UK) for $1 \mathrm{~h}$ at $37^{\circ} \mathrm{C}$, and then with Alexa Fluor 488 -conjugated anti-mouse antibody (1:1000; Invitrogen) for $1 \mathrm{~h}$ at $37^{\circ} \mathrm{C}$. The effects of anti-VCAM-1-D6 IgG on endothelial cell activation were evaluated by incubating $2 \times 10^{5}$ HUVECs in the absence or presence of $20 \mathrm{ng} \mathrm{ml}^{-1} \mathrm{hTNF} \alpha$ (Millipore), $20 \mu \mathrm{g} \mathrm{ml}^{-1}$ control IgG or anti-VCAM-1-D6 IgG for $24 \mathrm{~h}$. After blocking with PBS containing 1\% BSA for $1 \mathrm{~h}$ at room temperature, the cells were incubated first with rabbit anti-ICAM-1 monoclonal antibody (1:500; Abcam) for $1 \mathrm{~h}$ at $37^{\circ} \mathrm{C}$, and then with an Alexa Fluor 488-conjugated anti-rabbit antibody (1:1000; Invitrogen) for $1 \mathrm{~h}$ at $37^{\circ} \mathrm{C}$. Samples were analyzed by flow cytometry using a FACSCalibur system (BD Biosciences, San Jose, CA, USA) with the aid of FlowJo software (TreeStar, Ashland, OR, USA).

\section{Immunoblot analysis}

Immunoblot analysis was performed as described previously, with minor modifications. ${ }^{29}$ Lysates of scrambled siRNA- or VCAM-1 siRNA-transfected HUVECs cultured in EGM in the presence of $20 \mathrm{ng} \mathrm{ml}^{-1}$ hTNF $\alpha$ were resolved by sodium dodecyl sulfatepolyacrylamide gel electrophoresis (SDS-PAGE) and transferred onto nitrocellulose membranes using a wet transfer system (GE Healthcare Life Sciences, Piscataway, NJ, USA). After blocking with Tris-buffered saline and Tween (10 mm Tris- $\mathrm{HCl}, \mathrm{pH} 7.5,150 \mathrm{~mm} \mathrm{NaCl}$ and $0.05 \%$ $(\mathrm{v} / \mathrm{v})$ Tween 20; TBST) containing 5\% (w/v) skim milk, the membranes were incubated with rabbit anti-VCAM-1 monoclonal antibody (1:1000; Abcam) or mouse anti- $\beta$-actin monoclonal antibody (1:1000; Santa Cruz Biotechnology, Santa Cruz, CA, USA) at $4{ }^{\circ} \mathrm{C}$ overnight and then with horseradish peroxidase (HRP)-conjugated goat anti-rabbit IgG (1:5000; Santa Cruz Biotechnology) or goat antimouse IgG (1:5000; Santa Cruz Biotechnology). Following several washes with TBST, protein bands were visualized using SuperSignal West Pico chemiluminescent substrate (Pierce, Rockford, IL, USA) according to the manufacturer's instructions.

\section{Preparation of anti-VCAM-1-D6 IgG and fusion protein VCAM-1-D6-Fc}

Preparation of anti-VCAM-1-D6 IgG and VCAM-1-D6 crystallizable fragment $(\mathrm{Fc})$ was performed as described previously, with minor modifications. ${ }^{30}$ Briefly, following production of anti-VCAM-1-D6 IgG and VCAM-1-D6-Fc in HEK293F cells using polyethylenimine (Polysciences, Washington, PA, USA), the culture medium was collected and purified by affinity chromatography on protein A Sepharose (GeneScript, Piscataway, NJ, USA). Protein concentration was determined using a NanoDrop spectrophotometer (Thermo, Wilmington, DE, USA). Samples were dialyzed against PBS and analyzed by SDS-PAGE and Coomassie Brilliant Blue staining. Aliquots of the final pooled fractions were stored at $-80^{\circ} \mathrm{C}$.

\section{Wound healing assay}

The wound healing assay was performed as described previously, with minor modifications. ${ }^{31}$ To investigate the effect of VCAM-1 knockdown on HUVEC migration, $3 \times 10^{4}$ HUVECs transfected with scrambled siRNA or VCAM-1 siRNA were plated in each well of an ImageLock 96-well plate (Essen Bioscience, Ann Arbor, MI, USA) and maintained in EGM containing $20 \mathrm{ng} \mathrm{ml}^{-1} \mathrm{hTNF} \alpha$ for $24 \mathrm{~h}$ at $37^{\circ} \mathrm{C}$. A scratch was made in the monolayer using a 96-pin WoundMaker (Essen Bioscience). To investigate the effect of anti-VCAM-1-D6 IgG on HUVEC migration, $3 \times 10^{4}$ HUVECs were plated in each well of an ImageLock 96-well plate and maintained in EGM containing $20 \mathrm{ng} \mathrm{ml}{ }^{-1} \mathrm{hTNF} \alpha$ for $24 \mathrm{~h}$ at $37^{\circ} \mathrm{C}$. Wounds were then made by a 96-pin WoundMaker. Following two washes with PBS, the wounded HUVEC cultures were incubated in the absence or presence of $20 \mu \mathrm{g} \mathrm{ml}^{-1}$ control IgG, monoclonal antibody to VCAM-1 Ig-like domain 1 (anti-VCAM-1-D1 antibody; 51-10C9, BD Biosciences) or anti-VCAM-1-D6 IgG for $10 \mathrm{~h}$ at $37^{\circ} \mathrm{C}$ and then stained with $0.2 \%$ (w/v) crystal violet (Sigma-Aldrich, St Louis, MO, USA). For quantitative analysis, images were captured $10 \mathrm{~h}$ after wounding using a Leica (Wetzlar, Germany) DM IL LED light microscope, and the distance migrated was measured manually. 


\section{Tube formation assay}

Tube formation assays were performed as described previously, with minor modifications. ${ }^{32}$ Briefly, $150 \mu$ l Matrigel (Corning, Tewksbury, MA, USA) was added to each well of 48-well plates and allowed to polymerize for $30 \mathrm{~min}$ at $37^{\circ} \mathrm{C}$. To investigate the effect of VCAM-1 knockdown on HUVEC tube formation, $1 \times 10^{5}$ HUVECs transfected with scrambled siRNA or VCAM-1 siRNA and maintained in EGM containing $20 \mathrm{ng} \mathrm{ml}^{-1} \mathrm{hTNF} \alpha$ for $24 \mathrm{~h}$ at $37^{\circ} \mathrm{C}$ were seeded onto the Matrigel-coated plates. To investigate the role of VCAM-1-D6 in HUVEC tube formation, $1 \times 10^{5}$ HUVECs cultured in EGM containing $20 \mathrm{ng} \mathrm{ml}^{-1} \mathrm{hTNF} \alpha$ for $24 \mathrm{~h}$ were seeded onto the Matrigel-coated plates and incubated in the absence or presence of 5, 10, 20 or $40 \mu \mathrm{g} \mathrm{ml}^{-1}$ VCAM-1-D6-Fc fusion protein or $40 \mu \mathrm{g} \mathrm{ml}^{-1} \mathrm{Fc}$ domain alone for $12 \mathrm{~h}$ at $37^{\circ} \mathrm{C}$. To determine the effect of anti-VCAM-1-D6 IgG on HUVEC tube formation, $1 \times 10^{5}$ HUVECs cultured in EGM containing $20 \mathrm{ng} \mathrm{ml}^{-1} \mathrm{hTNF} \alpha$ for $24 \mathrm{~h}$ were seeded onto the Matrigelcoated plates and incubated in the absence or presence of $20 \mu \mathrm{g} \mathrm{ml}^{-1}$ control IgG, anti-VCAM-1-D1 IgG or anti-VCAM-1-D6 IgG for $12 \mathrm{~h}$ at $37^{\circ} \mathrm{C}$. To assess specific inhibition of tube formation by anti-VCAM-1-D6 IgG, antigen-antibody mixture was made by pre-incubating equimolar amounts of fusion protein VCAM-1-D6Fc and anti-VCAM-1-D6 IgG in PBS for $2 \mathrm{~h}$ at room temperature with gentle rotation. Then, $1 \times 10^{5}$ HUVECs cultured in EGM containing $20 \mathrm{ng} \mathrm{ml}^{-1} \mathrm{hTNF} \alpha$ for $24 \mathrm{~h}$ were seeded on Matrigel-coated plates and incubated in the absence or presence of control IgG, antiVCAM-1-D6 IgG or antigen-antibody mixture (1:1 molar ratio) for $12 \mathrm{~h}$ at $37^{\circ} \mathrm{C}$. Images were obtained using a light microscope (Leica DM IL LED), and tube formation was quantified by counting the total tube branches.

\section{Aortic ring sprouting assay}

Aortic rings were prepared from 7-week-old male Sprague Dawley rats (NARA Biotech, Seoul, Korea). Rats were anesthetized and bled out, and their thoracic aortas were removed and placed in a Petri dish filled with cold sterile PBS. Following removal of the surrounding fat tissue, the aortas were cut into 1-mm segments. Individual segments were embedded in $40 \mu$ l Matrigel (Corning) in 96-well tissue culture plates. Samples were allowed to gel in a $37^{\circ} \mathrm{C}$ incubator at $5 \% \mathrm{CO}_{2}$ for $30 \mathrm{~min}$, then an additional $40 \mu \mathrm{l}$ Matrigel was added to each well. For the TNF $\alpha$-induced aortic ring sprouting assay, the aortic segments were incubated in EGM alone, EGM containing $20 \mu \mathrm{g} \mathrm{ml}^{-1}$ control IgG or anti-VCAM-1-D6 IgG, EGM containing $20 \mathrm{ng} \mathrm{ml}^{-1}$ mouse TNF $\alpha$ (mTNF $\alpha$ ) or EGM containing $20 \mathrm{ng} \mathrm{m}^{-1} \mathrm{mTNF} \alpha$ together with $20 \mu \mathrm{g} \mathrm{ml}^{-1}$ control IgG or anti-VCAM-1-D6 IgG for 7 days. Images were captured using a light microscope (Leica DM IL LED), and the total numbers of vessels sprouting from each aortic ring were manually counted. To measure the lengths of the vessels, 10 fields per aortic ring were randomly selected and the vessel length was individually quantified using Image J software version 1.49j (National Institutes of Health).

\section{Cell viability assay}

For the cell viability assay, $5 \times 10^{3}$ HUVECs were plated in wells of a 96-well plate and incubated in EGM in the absence or presence of $20 \mu \mathrm{g} \mathrm{ml}^{-1}$ control IgG or anti-VCAM-1-D6 IgG or $36 \mu \mathrm{g} \mathrm{ml}^{-1}$ of 5-fluorouracil (5-FU) for $48 \mathrm{~h}$ at $37^{\circ} \mathrm{C}$. Cell viability was determined using a Cell Counting Kit-8 (Dojindo Laboratories, Kumamoto, Japan) according to the manufacturer's instructions. The final absorbance was measured at $450 \mathrm{~nm}$ using a VICTOR X4 microplate reader (PerkinElmer, Waltham, MA, USA).

\section{Immunocytochemistry}

For the immunocytochemistry analysis, $5 \times 10^{4}$ HUVECs were cultured in EGM on $0.1 \%(\mathrm{w} / \mathrm{v})$ gelatin-coated glass coverslips (Marienfeld-Superior, Lauda-Königshofen, Germany) at $37^{\circ} \mathrm{C}$ overnight. The cells were incubated in the absence or presence of $20 \mu \mathrm{g} \mathrm{ml}^{-1}$ control IgG or anti-VCAM-1-D6 IgG for $24 \mathrm{~h}$ at $37^{\circ} \mathrm{C}$. The cells were fixed in 4\% PFA, blocked by incubation in PBS containing $5 \%(\mathrm{v} / \mathrm{w})$ BSA and $0.1 \%(\mathrm{v} / \mathrm{v})$ Triton X-100 for $1 \mathrm{~h}$ at $37^{\circ} \mathrm{C}$, and then incubated with 1 unit per well rhodamine-phalloidin (Molecular Probes, Eugene, OR, USA) and $0.1 \mu \mathrm{g} \mathrm{ml}^{-1}$ Hoechst 33258 (Sigma-Aldrich) for $1 \mathrm{~h}$. Images were acquired with a FluoView FV300 confocal microscope (Olympus, Tokyo, Japan).

\section{Measurement of VCAM-1-mediated cell-cell contact}

VCAM-1-mediated cell-cell contact assays were performed as described previously, with minor modifications. ${ }^{31}$ Briefly, $1.5 \times 10^{7}$ HEK293F cells in suspension were transfected with plasmid encoding wild-type human VCAM-1 (WT-VCAM-1), cultured in Freestyle 293 expression medium overnight, and seeded at a density of $5 \times 10^{5}$ cells per well in six-well plates. Cells were maintained in the absence or presence of $20 \mu \mathrm{g} \mathrm{ml}^{-1}$ control IgG or anti-VCAM-1-D6 IgG for $2 \mathrm{~h}$. Cell aggregates (masses $>4$ cells) were counted in at least 10 fields using a light microscope (Leica DM IL LED).

\section{Cell enzyme-linked immunosorbent assay}

Cell enzyme-linked immunosorbent assays (ELISAs) were performed as described previously, with minor modifications. ${ }^{31}$ Briefly, $1 \times 10^{4}$ HUVECs plated in wells of a 96-well plate were cultured in EGM containing $20 \mathrm{ng} \mathrm{ml}^{-1}$ of hTNF $\alpha$ for $24 \mathrm{~h}$ at $37^{\circ} \mathrm{C}$. Following fixation with $4 \% \mathrm{PFA}$, cells were incubated with various concentrations $\left(0-50 \mu \mathrm{g} \mathrm{ml}^{-1}\right)$ of VCAM-1-D6-Fc-HRP or Fc-HRP for $2 \mathrm{~h}$ at $37^{\circ} \mathrm{C}$. For competition cell ELISA, HUVECs cultured in EGM containing $20 \mathrm{ng} \mathrm{ml}^{-1}$ of hTNF $\alpha$ were incubated with $3 \mu \mathrm{g} \mathrm{ml}^{-1}$ VCAM-1-D6-Fc-HRP in the absence or presence of increasing concentrations of anti-VCAM-1-D6 IgG for $2 \mathrm{~h}$ at $37^{\circ} \mathrm{C}$. After three washes with ice-cold PBS, the cells were incubated with $3,3^{\prime}, 5,5^{\prime}$ tetramethylbenzidine substrate solution (BD Biosciences). Optical density was measured at $450 \mathrm{~nm}$ using a VICTOR X4 plate reader.

\section{ELISA}

ELISA was performed as described previously, with minor modifications. ${ }^{33}$ Microplates (96-well) were coated with $0.1 \mu \mathrm{g}$ recombinant human VCAM-1 extracellular domain (Sino Biological Inc, Beijing, China) in PBS overnight at $37^{\circ} \mathrm{C}$. Then, the plates were washed three times with PBS and incubated with $3 \%(\mathrm{w} / \mathrm{v})$ BSA in PBS for $1 \mathrm{~h}$ at $37^{\circ} \mathrm{C}$. For the competition assay with anti-VCAM-1-D6 IgG, $1 \mu \mathrm{g}$ VCAM-1-D6-Fc-HRP was incubated with recombinant human VCAM-1 extracellular domain in the absence or presence of increasing concentrations of anti-VCAM-1-D6 IgG for $2 \mathrm{~h}$ at room temperature. Following three washes with PBS, $100 \mu \mathrm{l}$ of 3,3',5,5'-tetramethylbenzidine substrate solution were added to each well. Optical density was measured at $450 \mathrm{~nm}$ using a VICTOR X4 microplate reader.

\section{Statistical analysis}

All data were analyzed with GraphPad Prism 5.0 (GraphPad Software, La Jolla, CA, USA) using a two-tailed Student's $t$-test for comparison between two groups and a one-way analysis of variance with Bonferroni's correction for multiple comparisons. All data are presented as the mean \pm the standard error of the mean (s.e.m.). Values of $P<0.05$ were considered statistically significant. 

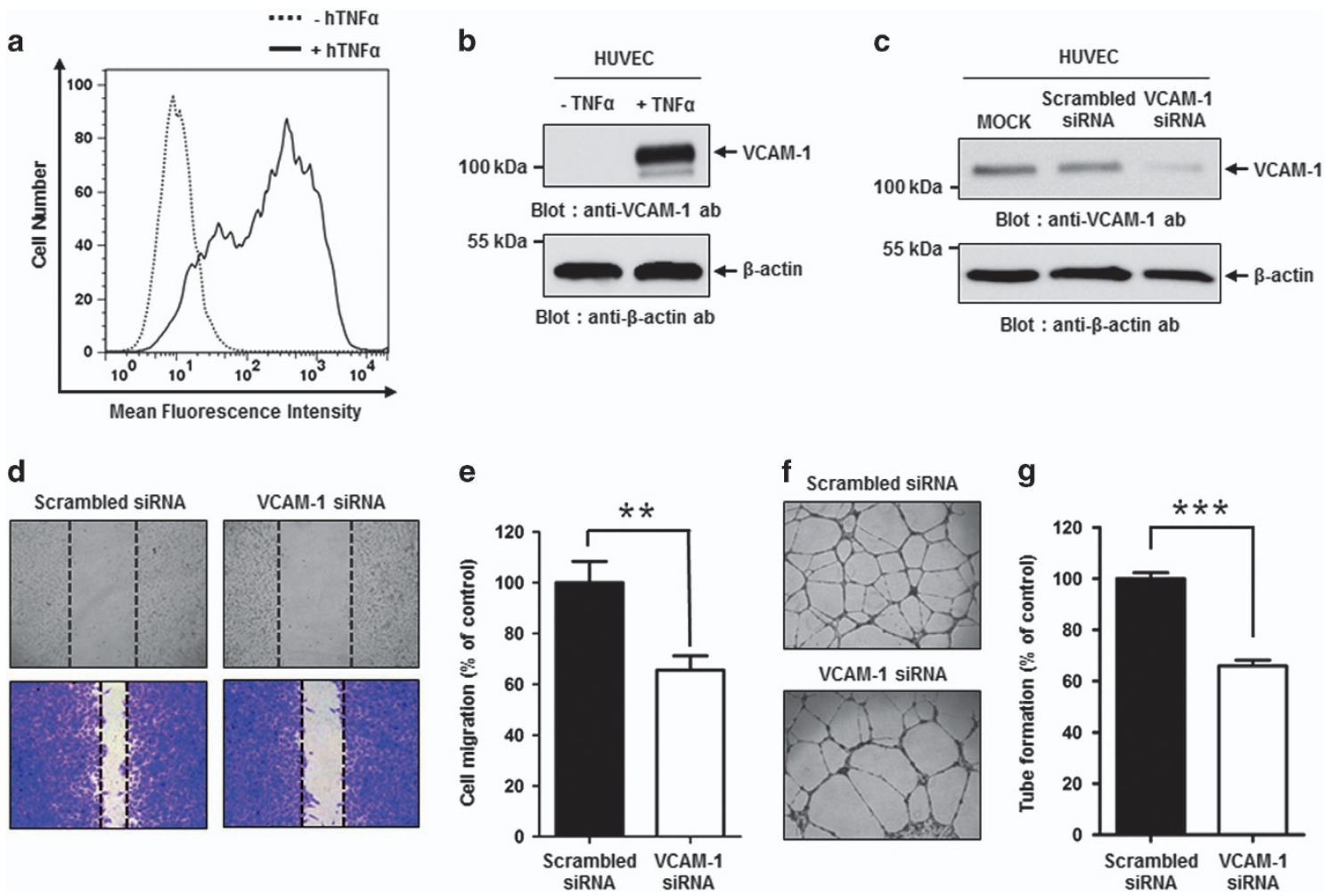

Figure 1 Effect of VCAM-1 knockdown on HUVEC migration and tube formation. (a) HUVECs were incubated in EGM in the absence (dashed line) or presence (solid line) of $20 \mathrm{ng} \mathrm{ml}^{-1}$ hTNF $\alpha$ for $24 \mathrm{~h}$. Cells were stained with anti-VCAM-1 monoclonal antibody, and VCAM-1 expression was analyzed using flow cytometry. (b) Representative immunoblot showing relative VCAM-1 expression levels on HUVECs cultured in EGM in the absence or presence of hTNF $\alpha$. (c) Representative immunoblot showing relative VCAM-1 expression levels following mock transfection of HUVECs or transfection with scrambled siRNA or VCAM-1 siRNA cultured in EGM in the presence of hTNF $\alpha$. $\beta$-actin was used as a loading control. (d) Light microscopy images depicting migration in wound healing assay of scrambled siRNA- or VCAM-1 siRNA-transfected HUVECs cultured in EGM in the presence of hTNF $\alpha$. Images were captured at $0 \mathrm{~h}$ (top; unstained) and $10 \mathrm{~h}$ (bottom; stained with crystal violet). (e) Quantitation of migration of scrambled siRNA- or VCAM-1 siRNA-transfected HUVECs cultured in EGM in the presence of hTNF $\alpha$, expressed as a percent of scrambled siRNA migration, based on the distance separating wound margins. (f) Light microscopic images depicting tube formation by scrambled siRNA- and VCAM-1 siRNA-transfected HUVECs cultured in EGM in the presence of hTNF $\alpha$. (g) Quantitation of total tube branches in scrambled siRNA- or VCAM-1 siRNA-transfected HUVECs cultured in EGM in the presence of hTNF $\alpha$, expressed as a percent of tube formation in the presence of scrambled siRNA. All data are presented as the mean \pm s.e.m. of triplicate measurements from one of the three independent experiments; ${ }^{* *} P<0.01$, $* * * P<0.001$.

\section{RESULTS}

\section{VCAM-1 knockdown reduced TNF $\alpha$-induced HUVEC migration and tube formation}

To examine the relevance of VCAM-1 in TNF $\alpha$-induced angiogenesis, we first examined VCAM-1 expression on HUVECs cultured in the absence or presence of hTNF $\alpha$, a strong inducer of VCAM-1, using flow cytometry and immunoblot analysis (Figures 1a and b), and found markedly increased expression of VCAM-1 on TNF $\alpha$-treated HUVECs. We then carried out siRNA-mediated knockdown of VCAM-1 in HUVECs cultured in the presence of TNF $\alpha$ and confirmed reduced VCAM-1 expression by VCAM-1 siRNA using immunoblot analysis (Figure 1c). We also measured the effect of VCAM-1 knockdown on HUVEC migration (Figures 1d and e) and tube formation (Figures if and $\mathrm{g}$ ). We found that VCAM-1 knockdown significantly decreased both HUVEC migration and tube formation. Taken together, these results suggest that VCAM-1 may play a key role in the regulation of TNF $\alpha$-induced angiogenesis.

VCAM-1-D6 is a key domain specifically regulating TNFoinduced HUVEC tube formation

To investigate the role of VCAM-1-D6 in TNF $\alpha$-induced angiogenesis, we generated a fusion protein in which the VCAM-1-D6 domain was fused to the Fc domain of an IgG molecule (VCAM-1-D6-Fc). This fusion protein, shown to be $>90 \%$ pure by SDS-PAGE and Coomassie Brilliant Blue staining (Supplementary Figure S1a), was used in a competitive blocking experiment, treating HUVECs grown in the presence of TNFa with the fusion protein or the Fc domain alone as a negative control. We then determined the effect of VCAM-1D6 on HUVEC tube formation (Figures $2 \mathrm{a}$ and $\mathrm{b}$ ). Tube formation was specifically and significantly inhibited by increasing concentrations of VCAM-1-D6-Fc but not by the 
a

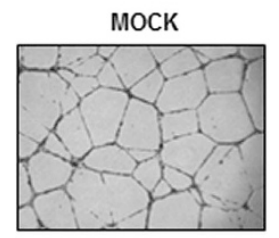

VCAM-1-D6-Fc $10 \mu \mathrm{g} / \mathrm{ml}$

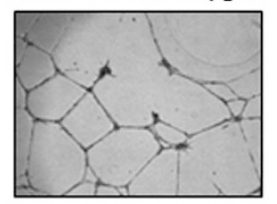

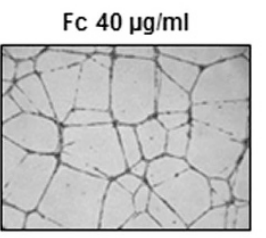
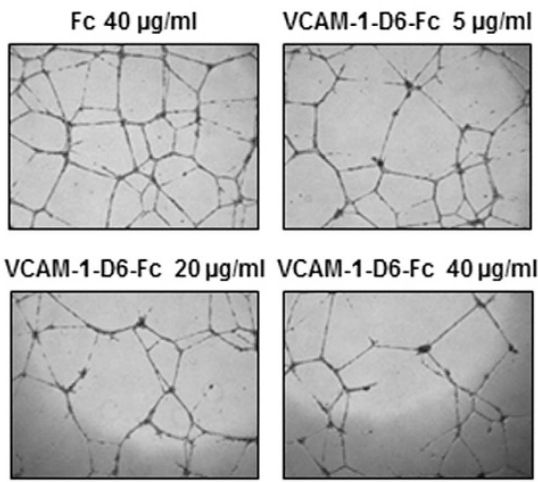

b

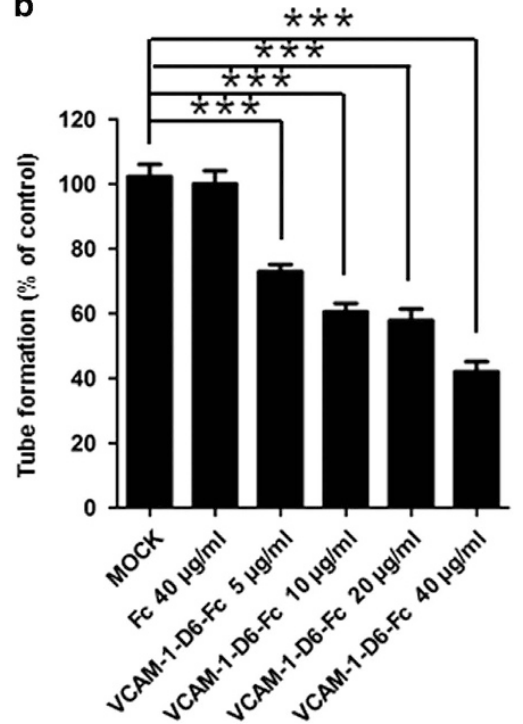

Figure 2 Effect of VCAM-1-D6 protein on HUVEC tube formation. (a) Light microscopic images depicting tube formation by hTNF $\alpha$-treated HUVECs in the absence (MOCK) or presence of the indicated concentrations of VCAM-1-D6-Fc fusion protein or Fc domain alone. Fc served as a negative control. (b) Quantitation of total tube branches in hTNF $\alpha$-treated HUVECs in presence of VCAM-1-D6-Fc or Fc, expressed as a percent of control (MOCK) tube formation. All data are presented as the mean \pm s.e.m. of triplicate measurements from one of the three independent experiments; ${ }^{* *} P<0.001$.

Fc domain alone. These data suggest that VCAM-1-D6 may be a key domain specifically regulating TNF $\alpha$-induced angiogenesis.

Anti-VCAM-1-D6 antibody specifically suppresses not only TNF $\alpha$-induced HUVEC migration and tube formation, but also $\mathrm{TNF} \alpha$-induced vessel sprouting from rat aorta

We previously reported that we generated a rabbit/human chimeric monoclonal antibody specific to VCAM-1-D6 (antiVCAM-1-D6 IgG) using phage display technology. To elucidate the effect of anti-VCAM-1-D6 IgG on TNF $\alpha$-induced angiogenesis, we treated HUVECs with control IgG, a monoclonal antibody to Ig-like domain 1 of VCAM-1 (anti-VCAM-1-D1 antibody) as a negative control, or anti-VCAM-1-D6 IgG in the presence of TNF $\alpha$ and then examined HUVEC migration (Figures $3 \mathrm{a}$ and $\mathrm{b}$ ) and tube formation (Figures $3 \mathrm{c}$ and $\mathrm{d}$ ). Anti-VCAM-1-D6 IgG was shown to be $>90 \%$ pure by SDS-PAGE and Coomassie Brilliant Blue staining (Supplementary Figure S1b). We found that HUVEC migration and tube formation were significantly and strongly inhibited by anti-VCAM-1-D6 IgG but not by control IgG, whereas antiVCAM-1-D1 had significant, but much less potent, inhibitory effects on these functions. These results demonstrated the potent inhibitory effect of anti-VCAM-1-D6 antibody on TNF $\alpha$-induced angiogenesis.

To confirm specific inhibition of TNF $\alpha$-induced tube formation by anti-VCAM-1-D6 IgG, we performed the TNF $\alpha$-induced HUVEC tube formation assays in the absence or presence of control IgG, anti-VCAM-1-D6 IgG or antibody-antigen mixture consisting of equimolar amounts of anti-VCAM-1-D6 IgG and VCAM-1-D6-Fc fusion protein
(Figures $3 \mathrm{e}$ and $\mathrm{f}$ ). Inhibition of tube formation by antiVCAM-1-D6 IgG was significantly attenuated in the presence of VCAM-1-D6-Fc, supporting the hypothesis that the antiVCAM-1-D6 antibody specifically inhibits TNF $\alpha$-induced vascular tube formation.

To further evaluate the effect of anti-VCAM-1-D6 IgG on $\mathrm{TNF} \alpha$-induced angiogenesis, we treated rat aortic rings with control IgG or anti-VCAM-1-D6 IgG in the absence or presence of TNF $\alpha$ and measured the number and length of vessels sprouting from the rat aortic rings (Figure $4 \mathrm{a}$ ). We found that in the presence of $\mathrm{TNF} \alpha$, many vessels sprouted from the rat aortic rings. Furthermore, we observed that anti-VCAM-1-D6 IgG prominently reduced the number (Figure 4b) and length (Figure 4c) of vessels that sprouted from rat aortic rings in the presence of $\mathrm{TNF} \alpha$, whereas the antibody did not suppress the sprouting of vessels from rat aortic rings in the absence of TNF $\alpha$. These results suggest that anti-VCAM-1-D6 antibody specifically inhibits TNF $\alpha$ induced angiogenesis.

Collectively, these data suggest that antibody targeting of VCAM-1-D6 may be effective for specifically suppressing $\mathrm{TNF} \alpha$-induced abnormal angiogenesis in vivo.

Anti-VCAM-1-D6 antibody does not affect HUVEC viability, morphology or activation

To evaluate the influence of anti-VCAM-1-D6 IgG on endothelial cell toxicity, we first determined the viability of HUVECs after treatment with anti-VCAM-1-D6 IgG. We found that anti-VCAM-1-D6 IgG had no cytotoxic effect on any of these cells, whereas 5-FU significantly reduced the viability of HUVECs (Figure 5a). Here, 
a

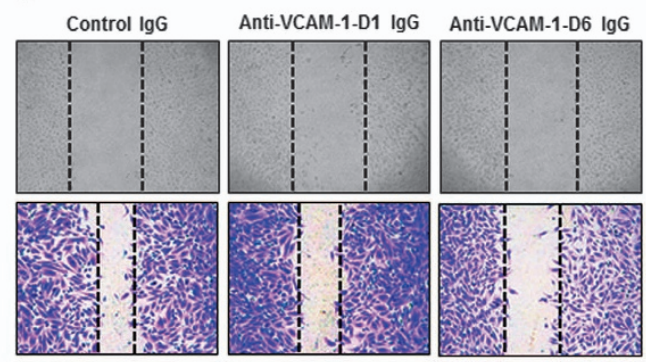

b

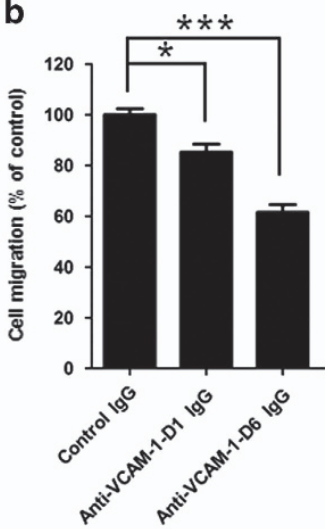

C

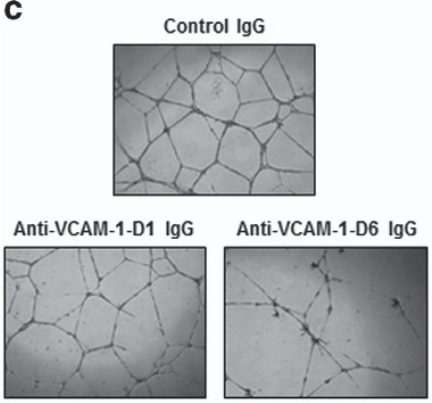

d

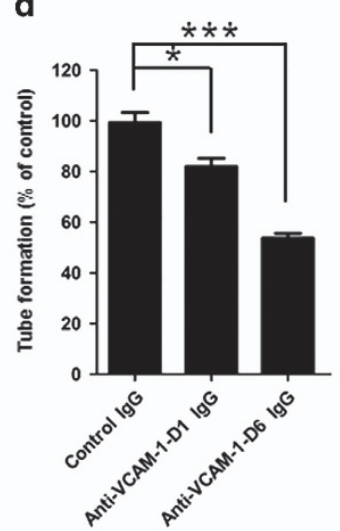

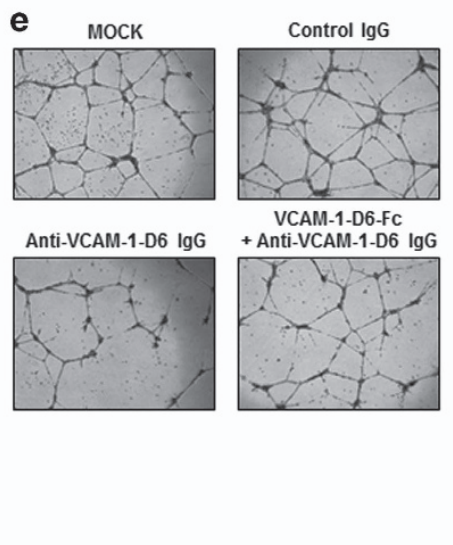

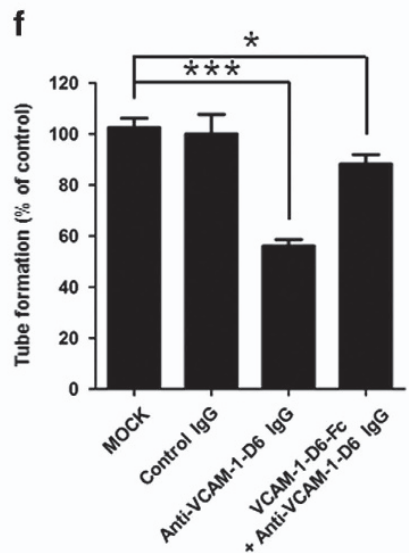

Figure 3 Effect of anti-VCAM-1-D6 IgG on HUVEC migration and tube formation. (a) Light microscopic images of hTNF $\alpha$-induced HUVEC migration in the presence of $20 \mu \mathrm{g} \mathrm{ml}^{-1}$ control IgG, anti-VCAM-1-D1 IgG and anti-VCAM-1-D6 IgG. Images were captured at $0 \mathrm{~h}$ (top; unstained) and $10 \mathrm{~h}$ (bottom; stained with crystal violet). (b) Quantitation of hTNFo-induced HUVEC migration in the presence of control IgG, anti-VCAM-1-D1 IgG and anti-VCAM-1-D6 IgG, expressed as a percent of distance migrated in the presence of control IgG, based on the distance separating wound margins. (c) Light microscopic images of tubes formed by hTNF $\alpha$-treated HUVECs in the presence of control IgG, anti-VCAM-1-D1 IgG and anti-VCAM-1-D6 IgG. (d) Quantitation of total tube branches from hTNF $\alpha$-treated HUVECs in the presence of control IgG, anti-VCAM-1-D1 IgG and anti-VCAM-1-D6 IgG, expressed as a percent of tube formation in the presence of control IgG. (e) Light microscopic images of tubes formed by hTNF $\alpha$-treated HUVECs in the absence (MOCK) or presence of $20 \mu \mathrm{g} \mathrm{ml}-1 \mathrm{control}$ IgG, anti-VCAM-1-D6 IgG and complex formed by anti-VCAM-1-D6 IgG and fusion protein VCAM-1-D6-Fc. (f) Quantitation of total tube branches, expressed as a percent of control (MOCK) tube formation. All data are presented as the mean \pm s.e.m. of triplicate measurements from one of the three independent experiments; ${ }^{*} P<0.05,{ }^{*} * * P<0.001$.

control IgG was used as a negative control. We also evaluated HUVEC morphology in the absence or presence of anti-VCAM-1-D6 IgG via immunocytochemistry. AntiVCAM-1-D6 IgG did not alter morphology of HUVECs (Figure 5b). To investigate the effect of anti-VCAM-1-D6 IgG on endothelial cell activation, an initial inflammatory response to harmful stimuli, we treated HUVECs with antiVCAM-1-D6 IgG and monitored HUVEC activation by measuring the expression of endothelial cell activation markers, including VCAM-1 and intercellular cell adhesion molecule-1 (ICAM-1). We used hTNF $\alpha$ as a positive control for endothelial cell activation. Anti-VCAM-1-D6 IgG had little effect on HUVEC activation, whereas hTNF $\alpha$, as expected, induced HUVEC activation (Figure 5c). Collectively, these data suggest that the antibody may cause insignificant endothelial cytotoxicity in vivo.
Anti-VCAM-1-D6 antibody specifically inhibits VCAM-1-mediated cell-cell contact by directly inhibiting VCAM-1-D6-mediated interactions between VCAM-1 molecules

To examine the mechanism of action of anti-VCAM-1-D6 IgG in TNF $\alpha$-induced angiogenesis, we overexpressed VCAM-1 in HEK293F cells, which do not express endogenous VCAM-1, and confirmed VCAM-1 expression using flow cytometry (Figure 6a). Then, we measured the number of cell aggregates, an indicator of VCAM-1-mediated cell-cell contact, in the presence of control IgG or anti-VCAM-1-D6 IgG (Figures 6b and $\mathrm{c}$ ). We found that the number of cell aggregates was $\sim 5$-fold greater in cells overexpressing VCAM-1 than in cells transfected with vector alone and that VCAM-1-mediated cell aggregation was substantially inhibited by anti-VCAM-1-D6 IgG but not by control IgG. These results suggest that 


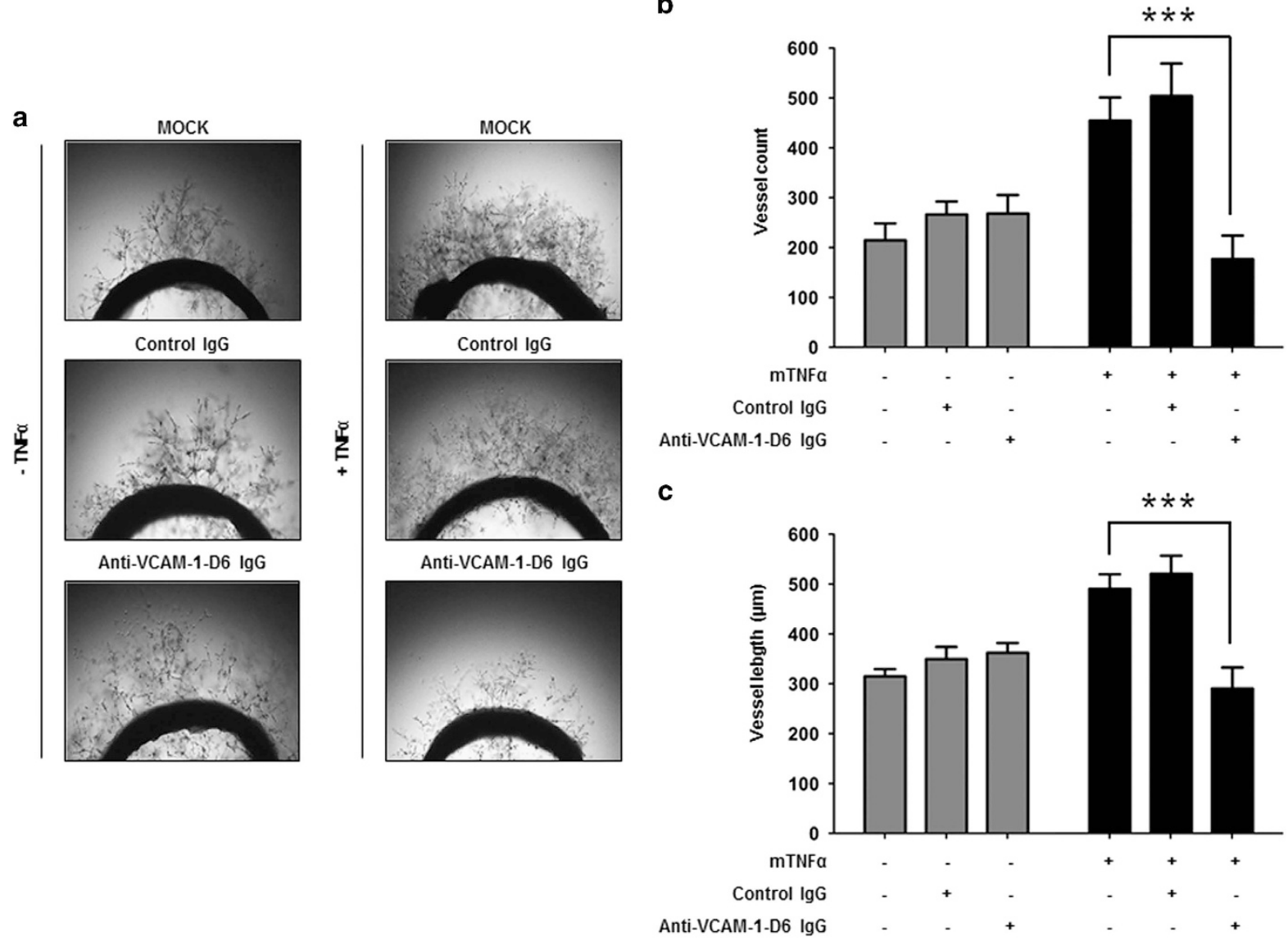

b

Figure 4 Effect of anti-VCAM-1-D6 IgG on TNF $\alpha$-induced vessel sprouting from rat aorta. (a) Rat aortic rings were incubated in EGM alone (MOCK), EGM containing $20 \mu \mathrm{g} \mathrm{ml}^{-1}$ control lgG or anti-VCAM-1-D6 IgG, EGM containing $20 \mathrm{ng} \mathrm{ml}^{-1} \mathrm{mTNF}^{-1}$ or EGM containing $20 \mathrm{ng} \mathrm{ml}^{-1} \mathrm{mTNF} \alpha$ together with $20 \mu \mathrm{g} \mathrm{ml} \mathrm{m}^{-1}$ control IgG or anti-VCAM-1-D6 lgG. Vessel outgrowth was monitored by light microscopy. (b) The number of vessels sprouting from each ring in a was counted and is expressed in the bar graph. (c) The length of vessels sprouting from each ring in a was measured and is expressed in the bar graph. Data are presented as the mean \pm s.e.m. of nine replicate measurements from one of the two independent experiments; ${ }^{* *} P<0.001$.

anti-VCAM-1-D6 antibody may specifically inhibit VCAM-1mediated endothelial cell-cell contact in TNFo-induced angiogenesis.

To further investigate the more detailed mode of action of anti-VCAM-1-D6 IgG at the molecular level, we first assayed the binding of VCAM-1-D6 to the surface of endothelial cells by incubating TNF $\alpha$-treated HUVECs in the absence or presence of increasing concentrations of HRP-conjugated VCAM-1-D6-Fc (VCAM-1-D6-Fc-HRP) or Fc (Fc-HRP) and then performing cell ELISAs (Figure 6d). The results showed that VCAM-1-D6-Fc-HRP, but not Fc-HRP, specifically and dose-dependently bound to TNF $\alpha$-treated HUVECs, suggesting the importance of VCAM-1-D6 on endothelial cell-cell contact. To investigate the blocking effect of anti-VCAM-1D6 IgG on the interaction between VCAM-1-D6 and activated endothelial cells, we incubated TNF $\alpha$-treated HUVECs with VCAM-1-D6-Fc-HRP in the absence or presence of increasing concentrations of anti-VCAM-1-D6 IgG and then performed cell ELISAs (Figure 6e). Anti-VCAM-1-D6 IgG significantly blocked the interactions between VCAM-1-D6-Fc-HRP and TNF $\alpha$-treated HUVECs. To further confirm the blocking effect of anti-VCAM-1-D6 IgG on the interaction between VCAM-1D6 and VCAM-1, ELISA plates were coated with recombinant human VCAM-1 extracellular domain, and VCAM-1-D6-FcHRP was then incubated in the plates in the absence and presence of increasing concentrations of anti-VCAM-1-D6 IgG (Figure 6f). We also confirmed that the direct interaction of VCAM-1-D6-Fc-HRP with the extracellular domain of recombinant human VCAM-1 was specifically inhibited by anti-VCAM-1-D6 IgG in a concentration-dependent manner. In summary, these data suggest that the anti-VCAM-1-D6 antibody may suppress endothelial cell-cell contact by directly inhibiting VCAM-1-D6-mediated interactions between VCAM-1 molecules on adjacent endothelial cells in TNF $\alpha$ induced angiogenesis.

\section{DISCUSSION}

Angiogenesis is the process by which new blood vessels form from pre-existing vessels and is pivotal in many biological processes, including development, reproduction and wound repair. Under pathological conditions, angiogenesis is regulated by the complex coordinated actions of multiple 
a

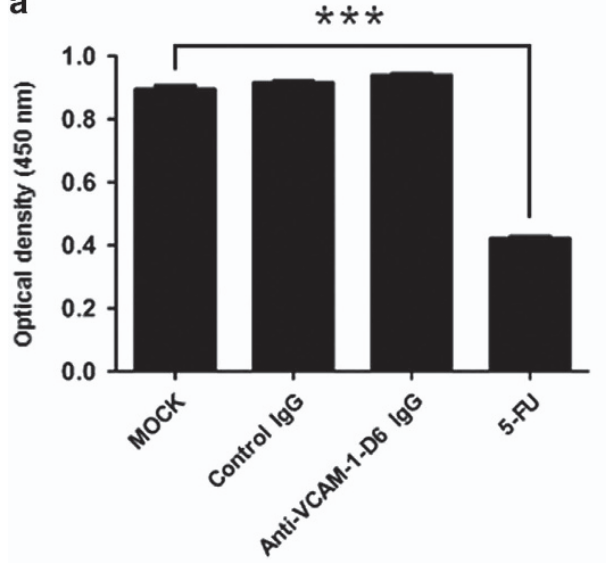

b

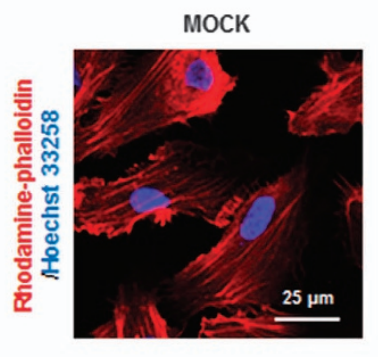

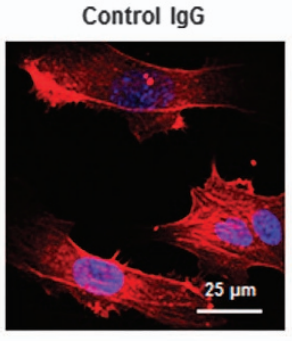

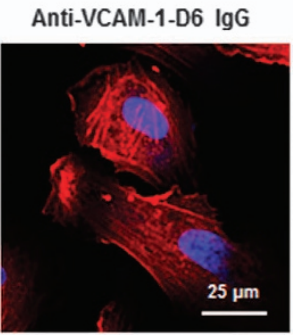

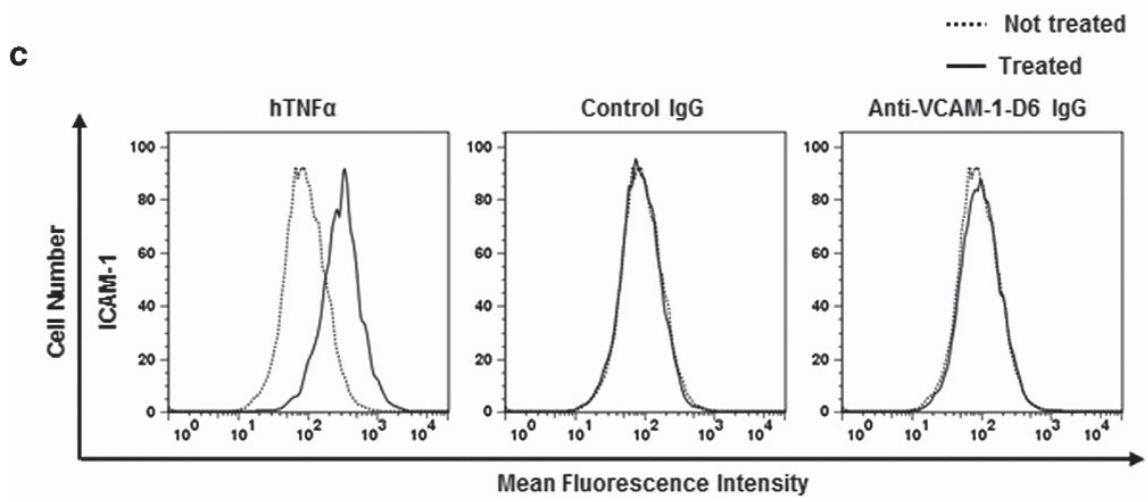

Figure 5 Effect of anti-VCAM-1-D6 IgG on HUVEC viability, morphology and activation. (a) HUVECs were incubated in the absence (MOCK) or presence of $20 \mu \mathrm{g} \mathrm{ml}^{-1}$ control IgG or anti-VCAM-1-D6 lgG or $36 \mu \mathrm{g} \mathrm{m}^{-1} 5$-FU for 2 days. Cell viability was assessed by measuring absorbance at $450 \mathrm{~nm}$. (b) HUVECs cultured in the absence (MOCK) or presence of control IgG or anti-VCAM-1-D6 IgG were stained with rhodamine-phalloidin (red) and nuclei were counterstained with Hoechst 33258 (blue), and then cells were examined by confocal microscopy. Scale bars represent $25 \mu \mathrm{m}$. (c) HUVECs cultured in the absence (dashed line) or presence (solid line) of hTNF $\alpha$, control IgG or anti-VCAM-1-D6 IgG were stained with anti-ICAM-1 monoclonal antibody and analyzed by flow cytometry. All data are presented as the mean \pm s.e.m. of triplicate measurements from one of the three independent experiments; ${ }^{* * *} P<0.001$.

pro- and anti-angiogenic regulators. ${ }^{5}$ Despite increasing attention to TNF $\alpha$-induced angiogenesis, novel therapeutic targets and their molecular mechanisms in TNF $\alpha$-induced angiogenesis have not been intensively studied yet. This is the first study to suggest that VCAM-1-D6 may be a novel potential angiogenic target in TNF $\alpha$-induced angiogenesis and that antibody-based modulation of VCAM-1-D6 may be an effective strategy for suppressing TNF $\alpha$-induced angiogenesis.

VCAM-1 is a type I transmembrane protein that is inducible and exclusively expressed on activated endothelial cells in response to extracellular stimuli, including numerous pro-inflammatory cytokines. ${ }^{20,21}$ VCAM-1 plays a key role in leukocyte binding to activated endothelial cells and transendothelial migration during inflammatory responses. Prior studies have suggested that VCAM-1 is closely associated with a variety of diseases, including cancers, atherosclerosis, arthritis and immune rejection. ${ }^{24-28}$ However, to date, the relevance and role of VCAM-1 in TNFo-induced angiogenesis have not been clearly identified. Here we propose that VCAM-1-D6 may play a key role and be a potential novel therapeutic target in TNF $\alpha$-induced angiogenesis. Several lines of evidence support our hypothesis. First, the results of VCAM-1 knockdown in TNF $\alpha$-treated HUVECs and VCAM-1 overexpression in HEK293F cells, which demonstrated VCAM-1-mediated cell-cell contact, imply the possible role of VCAM-1 in TNF $\alpha$-induced angiogenesis. Second, using competitive blocking experiments with a VCAM-1-D6 protein, we identified VCAM-1-D6 as a key domain regulating TNF $\alpha$-induced vascular tube formation. Third, we found that hTNF $\alpha$-induced HUVEC migration and tube formation were specifically inhibited by anti-VCAM-1-D6 IgG but not by control IgG. Fourth, VCAM-1-mediated cell-cell contact in HEK293 cells and VCAM-1-overexpressing HUVEC tube formation (Supplementary Figure S4) were specifically inhibited by anti-VCAM-1-D6 IgG but not by control IgG. Fifth, angiogenic sprouting from TNF $\alpha$-induced rat aortic rings was significantly inhibited by anti-VCAM-1-D6 IgG but not by control IgG. Sixth, the finding that VCAM-1-D6 protein or anti-VCAM-1D6 IgG significantly inhibited tube formation induced by TNF $\alpha$ (Supplementary Figure S3), but not by VEGF (Supplementary Figure S2) also suggests that VCAM-1 may be a major player in hTNF $\alpha$-induced, but not in VEGF- 
a

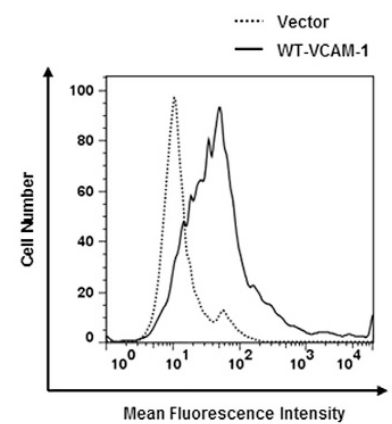

b
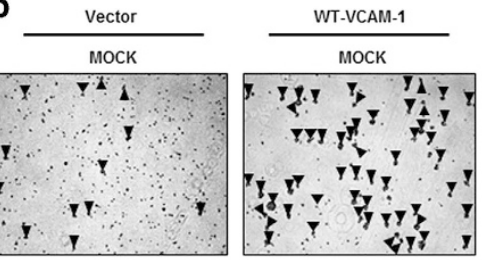

WT-VCAM-1
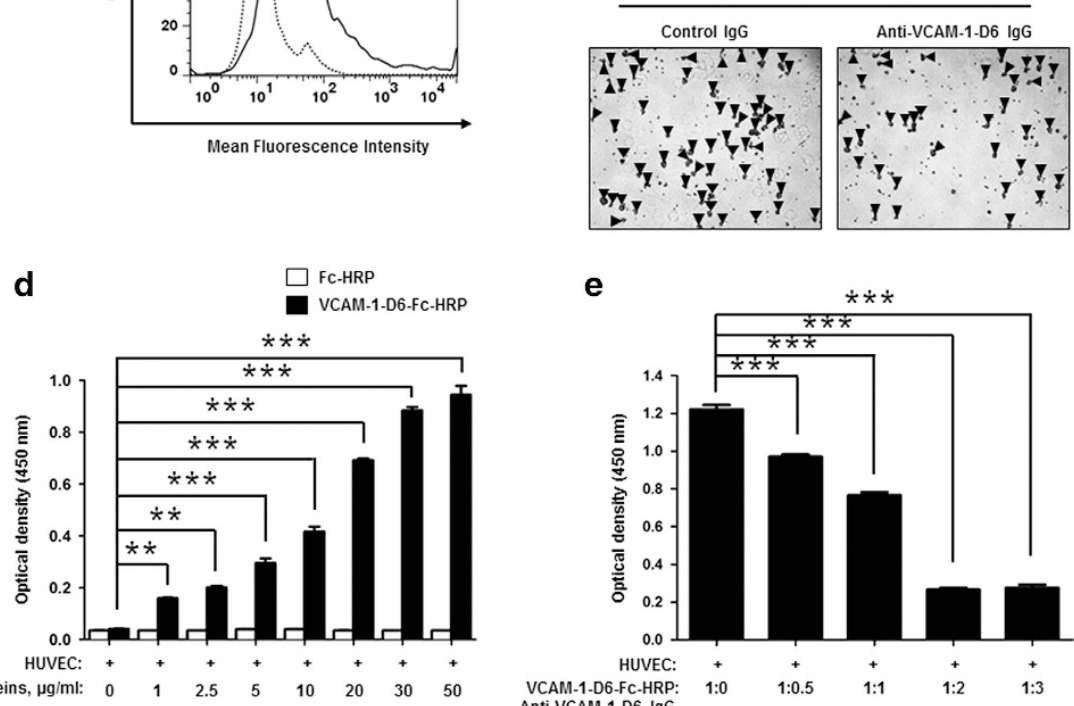

e

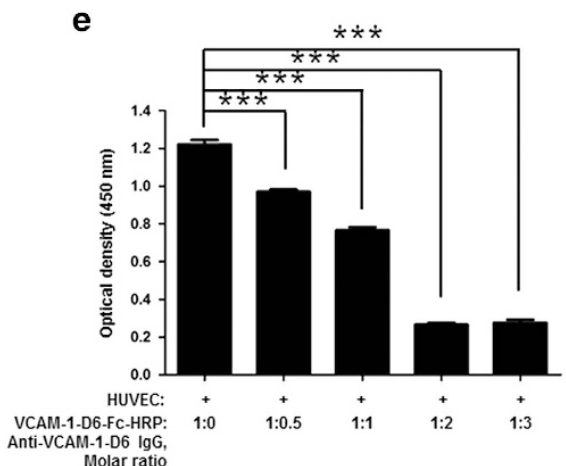

C

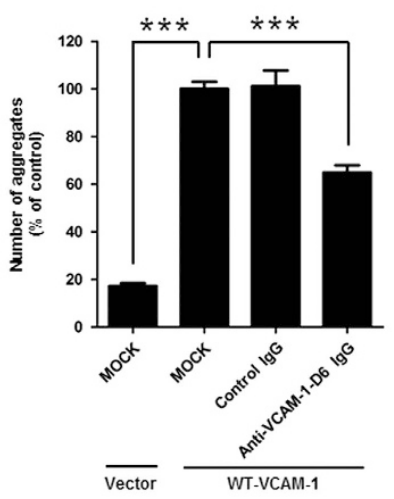

f

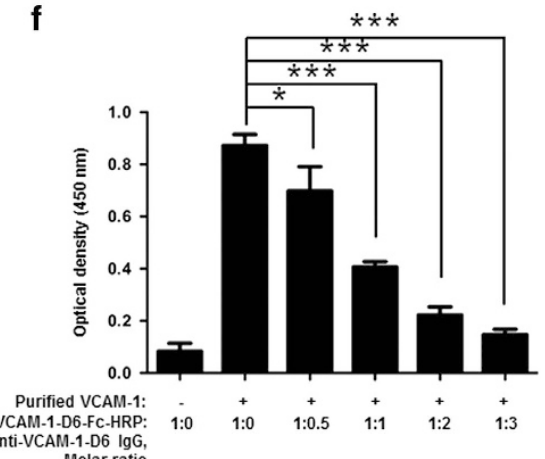

Figure 6 Effect of anti-VCAM-1-D6 IgG on clec14a-mediated cell-cell contact in VCAM-1-overexpressing HEK293F cells and hTNF $\alpha$ treated HUVECs. (a) HEK293F cells were transfected with vector alone or expression plasmid encoding WT-VCAM-1. Cells were stained with anti-VCAM-1 monoclonal antibody and VCAM-1 expression was analyzed using flow cytometry. (b) HEK293F cells transfected with vector alone or expression plasmid encoding WT-VCAM-1 were incubated in the absence (MOCK) or presence of $20 \mu \mathrm{g} \mathrm{ml}{ }^{-1}$ control IgG or anti-VCAM-1-D6 IgG. Cell aggregates (masses > 4 cells; triangular arrowheads) were counted under a light microscope. (c) Quantitation of aggregates formed in the transfected cells in the absence (MOCK) or presence of control IgG or anti-VCAM-1-D6 IgG expressed as a percent of control (MOCK) aggregate formation. (d) ELISA results of binding of the indicated concentrations of anti-VCAM-1-D6-FC-HRP and Fc-HRP to hTNF $\alpha$-treated HUVECs. (e) ELISA results of VCAM-1-D6-Fc-HRP binding, in the absence or presence of the increasing concentrations of anti-VCAM-1-D6 IgG, to hTNF $\alpha$-treated HUVECs pre-incubated with $3 \mu \mathrm{g} \mathrm{ml} \mathrm{I}^{-1}$ VCAM-1-D6-FC-HRP. (f) One tenth of a microgram of VCAM-1-D6-FC-HRP was pre-incubated with $1 \mu \mathrm{g}$ recombinant human VCAM-1 extracellular domain, and binding was determined by ELISA in the absence or presence of the increasing concentrations of anti-VCAM-1-D6 IgG. All data are presented as the mean \pm s.e.m. of triplicate measurements from one of three independent experiments; ${ }^{*} P<0.05,{ }^{* *} P<0.01,{ }^{* * *} P<0.001$.

induced angiogenesis. Seventh, similar to findings from hTNF $\alpha$-induced HUVEC tube formation assays, we also confirmed the significant inhibitory effect of anti-VCAM-1D6 IgG on hTNF $\alpha$-induced tube formation in human retinal endothelial cells (Supplementary Figure S5).

VCAM-1 forms complexes with several binding partners, including $\alpha 4 \beta 1$ integrin, moesin, ezrin, and secreted protein acidic and rich in cysteine. ${ }^{34-36}$ However, the direct binding partner of VCAM-1-D6 in TNFo-induced angiogenesis had not yet been identified. Here we suggest that VCAM-1-D6 may directly interact with VCAM- 1 and that this interaction is, at least in part, important for VCAM-1-mediated endothelial cell-cell contact in TNF $\alpha$-induced angiogenesis. Through the use of the cell aggregation assay, we demonstrated that VCAM-1-mediated cell-cell contact was specifically and significantly inhibited by anti-VCAM-1-D6 IgG but not by control IgG. Furthermore, we also demonstrated that HUVEC tube formation was increased by the overexpression of
VCAM-1 and that its increase was significantly inhibited by anti-VCAM-1-D6 IgG, but not by control IgG (Supplementary Figure S4). Our cell ELISA experiment also showed that VCAM-1-D6 bound specifically to the surface of TNFoactivated HUVECs and that this binding was specifically inhibited by anti-VCAM-1-D6 IgG in a concentrationdependent manner. Furthermore, we confirmed the direct interaction between purified VCAM-1-D6 and VCAM-1, and showed specific inhibition of this interaction by anti-VCAM1-D6 IgG. However, although we focused on the VCAM-1-D6mediated interaction between VCAM-1 molecules in TNFoinduced angiogenesis, we cannot exclude the possibility that VCAM-1 may bind to other binding partners implicated in this angiogenesis.

Monoclonal antibody-based therapy is now one of the most important strategies for treating patients with various diseases, including solid tumors, hematological malignancies, immunological disorders and eye diseases. As of November 2014, a total 
of 48 monoclonal antibodies had been approved in Europe and/or the United States for various indications, and many more are currently being evaluated in clinical trials. ${ }^{37}$ Although, most successful anti-angiogenic antibody drugs target VEGFdependent angiogenesis. ${ }^{6,7}$ TNF $\alpha$-induced angiogenesis is closely associated with the progression of several diseases, including cancer, wet AMD, and rheumatoid arthritis. ${ }^{8-13}$ On the basis of our present results, we suggest that antibody-based modulation of VCAM-1-D6 may be a novel and effective strategy to suppress TNF $\alpha$-induced abnormal angiogenesis in vivo. We previously reported that the anti-VCAM-1-D6 IgG we developed specifically binds, with subnanomolar affinity and broad cross-species reactivity, to VCAM-1-D6. ${ }^{30}$ In this study, we found that anti-VCAM-1-D6 IgG specifically and significantly inhibits angiogenic properties in vitro, including HUVEC migration, tube formation and VCAM-1-mediated cell-cell contact. Furthermore, we demonstrated that antiVCAM-1-D6 IgG also specifically inhibits TNF $\alpha$-induced vessel sprouting from rat aorta ex vivo, but not EGM-dependent vessel sprouting. We also found that the antibody seems to suppress VCAM-1-mediated endothelial cell-cell contact in TNF $\alpha$-induced angiogenesis by directly blocking VCAM-1-D6mediated interactions between VCAM-1 molecules on adjacent endothelial cells. Finally, we confirmed that anti-VCAM-1-D6 IgG had little effect on HUVEC viability, morphology or activation, suggesting that the antibody would be associated with a low level of endothelial cell toxicity in vivo.

In conclusion, we have shown that VCAM-1-D6 is a novel potential angiogenic target in TNF $\alpha$-induced angiogenesis and that antibody targeting of VCAM-1-D6 may be effective in suppressing TNFo-induced angiogenesis. On the basis of currently available evidence, we suggest a mode of action whereby, in pathological conditions that are predominantly affected by TNF $\alpha$-induced angiogenesis, anti-VCAM-1-D6 antibody binds to VCAM-1 expressed on the surface of TNF $\alpha$ activated endothelial cells and directly blocks VCAM-1-D6mediated interactions between VCAM-1 molecules on adjacent cells, resulting in efficient suppression of $\mathrm{TNF} \alpha$-induced angiogenesis. In future studies, we plan to investigate the mechanism of action of the anti-VCAM-1-D6 antibody and evaluate its in vivo efficacy in greater depth.

\section{CONFLICT OF INTEREST}

The authors declare no conflict of interest.

\section{ACKNOWLEDGEMENTS}

This work was supported by a research grant (10TS03) from the Scripps Korea Antibody Institute and partly by the Bio \& Medical Technology Development Program of the National Research Foundation funded by the Korean government (Ministry of Science, ICT and Future Planning) (2015M3A9D9074279).

1 Nowak JZ. Age-related macular degeneration (AMD): pathogenesis and therapy. Pharmacol Rep 2006; 58: 353-363.
2 Elshabrawy HA, Chen Z, Volin MV, Ravella S, Virupannavar S, Shahrara S. The pathogenic role of angiogenesis in rheumatoid arthritis. Angiogenesis 2015; 18: 433-448.

3 Folkman J. Diagnostic and therapeutic applications of angiogenesis research. C R Acad Sci III 1993; 316: 909-918.

4 Aref AA. Current management of glaucoma and vascular occlusive disease. Curr Opin Ophthalmol 2015; 27: 140-145.

5 Potente M, Gerhardt H, Carmeliet P. Basic and therapeutic aspects of angiogenesis. Cell 2011; 146: 873-887.

6 Hsu JY, Wakelee HA. Monoclonal antibodies targeting vascular endothelial growth factor: current status and future challenges in cancer therapy. BioDrugs 2009; 23: 289-304.

7 Syed BA, Evans JB, Bielory L. Wet AMD market. Nat Rev Drug Discov 2012; 11: 827.

8 Hammam O, Mahmoud O, Zahran M, Sayed A, Salama R, Hosny K et al. A possible role for TNF-alpha in coordinating inflammation and angiogenesis in chronic liver disease and hepatocellular carcinoma. Gastrointest Cancer Res 2013; 6: 107-114.

9 DeBusk LM, Chen Y, Nishishita T, Chen J, Thomas JW, Lin PC. Tie2 receptor tyrosine kinase, a major mediator of tumor necrosis factor alphainduced angiogenesis in rheumatoid arthritis. Arthritis Rheum 2003; 48: 2461-2471.

10 Xiao Z, Liu Q, Mao F, Wu J, Lei T. TNF-alpha-induced VEGF and MMP-9 expression promotes hemorrhagic transformation in pituitary adenomas. Int J Mol Sci 2011; 12: 4165-4179.

11 Theodossiadis PG, Liarakos VS, Sfikakis PP, Vergados IA, Theodossiadis GP. Intravitreal administration of the anti-tumor necrosis factor agent infliximab for neovascular age-related macular degeneration. Am J Ophthalmol 2009; 147: 825-830.

12 Lichtlen P, Lam TT, Nork TM, Streit T, Urech DM. Relative contribution of VEGF and TNF-alpha in the cynomolgus laser-induced CNV model: comparing the efficacy of bevacizumab, adalimumab, and ESBA105. Invest Ophthalmol Vis Sci 2010; 51: 4738-4745.

13 Lai KC, Liu CJ, Lin TJ, Mar AC, Wang HH, Chen CW et al. Blocking TNFalpha inhibits angiogenesis and growth of IFIT2-depleted metastatic oral squamous cell carcinoma cells. Cancer Lett 2016; 370: 207-215.

14 Welti J, Loges S, Dimmeler S, Carmeliet P. Recent molecular discoveries in angiogenesis and antiangiogenic therapies in cancer. J Clin Invest 2013; 123: 3190-3200.

15 Chong V. Ranibizumab for the treatment of wet AMD: a summary of realworld studies. Eye (Lond) 2015; 30: 270-286.

16 Solomon SD, Lindsley KB, Krzystolik MG, Vedula SS, Hawkins BS. Intravitreal bevacizumab versus ranibizumab for treatment of neovascular age-related macular degeneration: findings from a Cochrane systematic review. Ophthalmology 2015; 123: 70-77.

17 Yazdi MH, Faramarzi MA, Nikfar S, Falavarjani KG, Abdollahi M. Ranibizumab and aflibercept for the treatment of wet age-related macular degeneration. Expert Opin Biol Ther 2015; 15: 1349-1358.

18 Kopetz S, Hoff PM, Morris JS, Wolff RA, Eng C, Glover KY et al. Phase II trial of infusional fluorouracil, irinotecan, and bevacizumab for metastatic colorectal cancer: efficacy and circulating angiogenic biomarkers associated with therapeutic resistance. J Clin Oncol 2010; 28: 453-459.

19 Lucio-Eterovic AK, Piao Y, de Groot JF. Mediators of glioblastoma resistance and invasion during antivascular endothelial growth factor therapy. Clin Cancer Res 2009; 15: 4589-4599.

20 Carlos TM, Schwartz BR, Kovach NL, Yee E, Rosa M, Osborn L et al. Vascular cell adhesion molecule-1 mediates lymphocyte adherence to cytokine-activated cultured human endothelial cells. Blood 1990; 76: 965-970.

21 Lee S, Chung J, Ha IS, Yi K, Lee JE, Kang HG et al. Hydrogen peroxide increases human leukocyte adhesion to porcine aortic endothelial cells via NFkappaB-dependent up-regulation of VCAM-1. Int Immunol 2007; 19: 1349-1359.

22 Polte T, Newman W, Raghunathan G, Gopal TV. Structural and functional studies of full-length vascular cell adhesion molecule-1: internal duplication and homology to several adhesion proteins. DNA Cell Biol 1991; 10: 349-357.

23 Ulbrich $H$, Eriksson EE, Lindbom L. Leukocyte and endothelial cell adhesion molecules as targets for therapeutic interventions in inflammatory disease. Trends Pharmacol Sci 2003; 24: 640-647.

24 Gorcyznski RM, Chung S, Fu XM, Levy G, Sullivan B, Chen Z. Manipulation of skin graft rejection in alloimmune mice by anti-VCAM-1:VLA-4 but not anti-ICAM-1:LFA-1 monoclonal antibodies. Transpl Immunol 1995; 3: 55-61. 
25 Kanwar JR, Kanwar RK, Wang D, Krissansen GW. Prevention of a chronic progressive form of experimental autoimmune encephalomyelitis by an antibody against mucosal addressin cell adhesion molecule-1, given early in the course of disease progression. Immunol Cell Biol 2000; 78: 641-645.

26 Stegall MD, Dean PG, Ninova D, Cohen AJ, Shepard GM, Gup C et al. alpha4 integrin in islet allograft rejection. Transplantation 2001; 71 : 1549-1555.

27 Carter RA, Campbell IK, O'Donnel KL, Wicks IP. Vascular cell adhesion molecule-1 (VCAM-1) blockade in collagen-induced arthritis reduces joint involvement and alters B cell trafficking. Clin Exp Immunol 2002; 128 : 44-51.

28 Cybulsky MI, liyama K, Li H, Zhu S, Chen M, liyama M et al. A major role for VCAM-1, but not ICAM-1, in early atherosclerosis. J Clin Invest 2001; 107: $1255-1262$.

29 Lee S, Kim JH, Lee CS, Kim Y, Heo K, Ihara Y et al. Collapsin response mediator protein-2 inhibits neuronal phospholipase $D(2)$ activity by direct interaction. J Biol Chem 2002; 277: 6542-6549.

30 Lee S, Yoon IH, Yoon A, Cook-Mills JM, Park CG, Chung J. An antibody to the sixth Ig-like domain of VCAM-1 inhibits leukocyte transendothelial migration without affecting adhesion. J Immunol 2012; 189: 4592-4601.

$31 \mathrm{Ki}$ MK, Jeoung MH, Choi JR, Rho SS, Kwon YG, Shim H et al. Human antibodies targeting the C-type lectin-like domain of the tumor endothelial cell marker clec14a regulate angiogenic properties in vitro. Oncogene 2013; 32: 5449-5457.

$32 \mathrm{Kim}$ TK, Na HJ, Lee WR, Jeoung MH, Lee S. Heat shock protein 70-1A is a novel angiogenic regulator. Biochem Biophys Res Commun 2015; 469: 222-228.

33 Kim TK, Park CS, Jeoung MH, Lee WR, Go NK, Choi JR et al. Generation of a human antibody that inhibits TSPAN8-mediated invasion of metastatic colorectal cancer cells. Biochem Biophys Res Commun 2015; 468: 774-780.

34 Klemke M, Weschenfelder T, Konstandin MH, Samstag Y. High affinity interaction of integrin alpha4betal (VLA-4) and vascular cell adhesion molecule 1 (VCAM-1) enhances migration of human melanoma cells across activated endothelial cell layers. J Cell Physiol 2007; 212: 368-374.

35 Kelly KA, Allport JR, Yu AM, Sinh S, Sage EH, Gerszten RE et al. SPARC is a VCAM-1 counter-ligand that mediates leukocyte transmigration. J Leukoc Biol 2007; 81: 748-756.

36 Barreiro O, Yanez-Mo M, Serrador JM, Montoya MC, Vicente-Manzanares M, Tejedor R et al. Dynamic interaction of VCAM-1 and ICAM-1 with moesin and ezrin in a novel endothelial docking structure for adherent leukocytes. J Cell Biol 2002; 157: 1233-1245.

37 Ecker DM, Jones SD, Levine HL. The therapeutic monoclonal antibody market. MAbs 2015; 7: 9-14.

(c) (1) \&) This work is licensed under a Creative Commons Attribution-NonCommercial-NoDerivs 4.0 International License. The images or other third party material in this article are included in the article's Creative Commons license, unless indicated otherwise in the credit line; if the material is not included under the Creative Commons license, users will need to obtain permission from the license holder to reproduce the material. To view a copy of this license, visit http://creativecommons.org/licenses/by-nc-nd/4.0/

Supplementary Information accompanies the paper on Experimental \& Molecular Medicine website (http://www.nature.com/emm) 